\title{
Acrp30 inhibits leptin-induced metastasis by downregulating the JAK/STAT3 pathway via AMPK activation in aggressive SPEC-2 endometrial cancer cells
}

\author{
XIAOMEI WU ${ }^{1,2}$, QIN YAN $^{1}$, ZHENBO ZHANG $^{2}$, GUIQIANG DU $^{1}$ and XIAOPING WAN ${ }^{1}$ \\ ${ }^{1}$ International Peace Maternity and Child Health Hospital, Shanghai Jiao Tong University, \\ Shanghai 200030; ${ }^{2}$ Department of Gynecology and Obstetrics, Shanghai Jiao Tong \\ University Affiliated First People's Hospital, Shanghai 200083, P.R. China
}

Received November 5, 2011; Accepted December 12, 2011

DOI: $10.3892 /$ or.2012.1670

\begin{abstract}
Obesity is a well-established risk factor for endometrial cancer, due in part to the adipokines generated by adipose tissue, such as adiponectin (also known as Acrp30) and leptin, which are associated with many endocrine-related cancers. Recent reports suggested that Acrp30 inhibits leptin-stimulated cell proliferation in HEC-1A and RL95-2 endometrial cancer cell lines, and that the serum leptin/Acrp30 ratio plays an important role in endometrial cancer development. We explored whether Acrp30 could reverse the leptin-induced metastasis phenotype in the SPEC-2 endometrial cancer cell line. Transcripts for Acrp30 receptors (AdipoR1 and AdipoR2) and leptin receptor $(O b-R b)$ were detected by quantitative realtime RT-PCR (qRT-PCR) in six endometrial cancer cell lines. Leptin $(1 \mu \mathrm{g} / \mathrm{ml})$ treatment stimulated SPEC-2 cell proliferation by inducing cell cycle arrest and apoptosis, while Acrp30 $(10 \mu \mathrm{g} / \mathrm{ml})$ treatment inhibited the growth of SPEC-2 cells. Importantly, Acrp30 was able to inhibit leptin-induced SPEC-2 cell proliferation. Leptin promoted SPEC-2 cell invasion in a Matrigel transwell assay, while Acrp30 partly suppressed the invasion stimulated by leptin. To investigate the molecular mechanism underlying this phenomenon, we monitored the AMPK and JAK/STAT3 signaling pathways by western blotting and cell immunofluorescence. Acrp30 reduced leptin-induced STAT3 phosphorylation and nuclear translocation via activation of the MAPK pathway. AG490 (JAK/STAT3 inhibitor) reduced MMP-2 and MMP-9 protein levels in cells treated with leptin, while IL-6 (JAK/STAT3 stimulator) and Compound C (AMPK inhibitor) elevated MMP-2 and MMP-9 protein levels in cells treated with Acrp30. In conclusion, we demonstrated that
\end{abstract}

Correspondence to: Dr Xiaoping Wan, International Peace Maternity and Child Health Hospital, Shanghai Jiao Tong University, No. 910, Hengshan Road, Shanghai 200030, P.R. China

E-mail:wanxiaoping61@yahoo.com.cn

Key words: adiponectin, leptin, STAT3, AMPK, endometrial neoplasms
Acrp30 effectively reversed the invasion stimulated by leptin, and AMPK and JAK/STAT3 pathways mediated the invasive phenotype of SPEC-2 cells.

\section{Introduction}

Obesity is one of the well-established risk factors for endometrial cancer (1). The factor which links obesity with endometrial cancer appears to be excessive exposure to various bioactive substances produced by adipose tissue (2). Estrogens, insulin and insulin-like growth factors (IGFs) are believed to be involved in endometrial tumorigenesis $(3,4)$. In addition to these factors, adipose tissue produces various bioactive substances called adipokines, the most prominent of which are leptin and adiponectin (Acrp30). The aberrant production of leptin and Acrp30 are all related to the development and progression of many obesity-related cancers including endometrial cancer (5-7).

Acrp30 is a 30-kDa protein with several metabolic activities, including anti-diabetic, anti-inflammatory and anti-atherogenic functions, and was shown recently to have anti-tumor effects in several types of cancer (8). It is the most abundant protein synthesized by adipose tissue, with plasma concentrations ranging from 2 to $30 \mu \mathrm{g} / \mathrm{ml}$ (9), but is paradoxically reduced in obesity and thus generally found to be negatively correlated with body fat mass (10). The effect of Acrp30 is mediated through two known receptors, AdipoR1 and AdipoR2. Many tumor cell lines including those derived from the endometrium also express both receptors $(11,12)$. In animal models, Acrp30 deprivation promotes tumor growth through mobilization of circulating endothelial progenitor cells, making the tumor cells more aggressive (13).

Leptin on the other hand, is a $16-\mathrm{kDa}$ protein, the concentration of which in the blood is positively related to body fat mass or body weight and is thus found to be elevated in obesity (10). In addition to its function in regulation of energy balance (14), reproduction, immunity (15), and inflammation (16), leptin also plays an important role in cancer development (10). The functions of leptin are mediated via the signaling-competent long form of the leptin receptor $(\mathrm{Ob}-\mathrm{Rb})$, which is expressed by many tissues including tumor cell lines (17). 
Accumulating evidence have suggested that the L(leptin)/ $\mathrm{A}($ Acrp30) ratio is positively associated with several malignancies, and independently associated with an increased risk for endometrial cancer development $(18,19)$. The balance of leptin and Acrp30 levels in individuals, rather than the leptin or Acrp30 levels alone, may indicate such physiological changes as the development of cancer (20). In addition, these two opposing adipokines may each downregulate the other pathway via suppressing the mRNA expression of the corresponding receptors in MCF-7 cells (8).

A growing number of human malignancies and tumor formation are associated with high levels of activation of signal transducers and activators of transcription (STATs), very frequently STAT3 (21). Previous studies suggested that leptin increases STAT3 phosphorylation, which in turn promotes cell proliferation and inhibits cell apoptosis through binding to its target genes (22), and may increase nuclear translocation of active STAT3 in MCF-7 cells (23). There have been two canonical signaling pathways identified for Acrp30, one of which is through the activation of AM-activated protein kinase (AMPK) (24). Acrp30-repressed proliferation of breast cancer cells is mediated through stimulation of AMPK activity by phosphorylation at $\operatorname{Thr} 172(10,25,26)$.

Although the anti-proliferative function of Acrp30 and the pro-proliferative function of leptin were reported in other studies, their effects on cell invasion is not well described. This study was designed to investigate the hypothesis that Acrp30 can inhibit leptin-induced cell invasion in human endometrial cancer cell lines and to explore the potential underlying molecular mechanisms. We investigated the novel cross-talk between leptin-induced JAK/STAT3 pathways and the Acrp30 activated AMPK pathway. This observation may lead to new insights into anti-adipokine therapy for obesity-related cancers such as endometrial cancer.

\section{Material and methods}

Materials. Recombinant human Acrp30, IL-6 and leptin were purchased from Pepro Tech (Rocky Hill, NJ, USA). Compound $\mathrm{C}$ and AG490 were purchased from Sigma-Aldrich (St. Louis, MO, USA). The anti-STAT3, anti-phospho-STAT3 (Ser727), anti-AMPK $\alpha$, anti-phospho-AMPK $\alpha$ (Thr172), anti-MMP-2 and anti-MMP-9 monoclonal antibodies for western blot and immunofluorescence assays were obtained from Cell Signaling Technology (Beverly, MA, USA).

Cell culture. The Ishikawa cell line was obtained from the American Type Culture Collection (Manassas, VA, USA), and the SPEC-2 cell line was preserved by the Gynecology and Obstetrics Laboratory of Shanghai First People's Hospital. The SPEC- 2 cell line was derived from a poorly-differentiated uterine serous papillary carcinoma (USPC; type II endometrial carcinoma). All cell lines were cultured in Dulbecco's modified Eagle's medium (DMEM) supplemented with 10\% fetal bovine serum (FBS) plus penicillin $(100 \mathrm{U} / \mathrm{ml})$ and streptomycin $(100 \mu \mathrm{g} / \mathrm{ml})$ in a humidified incubator at $37^{\circ} \mathrm{C}$ in $5 \%$ $\mathrm{CO}_{2}$ atmosphere.

Proliferation assay. Ishikawa and SPEC-2 cells were seeded in 96 -well plates at a density of $5 \times 10^{3}$ cells/well in complete
Table I. Sequences of primers used for amplification of target genes.

\begin{tabular}{ll}
\hline Gene & \multicolumn{1}{c}{ Primer nucleotide sequence } \\
\hline Adipo R1 & F: 5'-TTCTTCCTCATGGCTGTGATGT-3' \\
& R: 5'-AGTGGACAAAGGCTGCTGCCA-3' \\
Adipo R2 & F: 5'-ATGAACGAGCCAACAGAAAACCGA-3' \\
& R: 5'-CGGTGTCCATGCAAGAGGAAGTCA-3' \\
Ob-Rb & F: 5'-GTGAAGCCTGATCCACCATT-3' \\
& R: 5'-CCTCATACGAAGACCCAGGA-3' \\
GAPDH & F: 5'-GAGTCAACGGATTTGGTCGT-3' \\
& R: 5'-TTGATTTTGGAGGGATCTCG-3' \\
\hline
\end{tabular}

medium. After $24 \mathrm{~h}$ of culture, the medium was replaced with serum-free DMEM and starved for a further $16 \mathrm{~h}$ before the cells were exposed to fresh serum-free medium containing recombinant human Acrp30 at 0.1, 1, 10, and $20 \mu \mathrm{g} / \mathrm{ml}$, human recombinant leptin at $0.01,0.1,1,2 \mu \mathrm{g} / \mathrm{ml}$, or both Acrp30 and leptin (10 and $1 \mu \mathrm{g} / \mathrm{ml}$, respectively). After 24,48 , and $72 \mathrm{~h}$, MTT (3-(4,5)-dimethylthiahiazo (-z-yl)-3,5-di-phenytetrazoliumromide) solution ( $20 \mu 1$ of $5 \mathrm{mg} / \mathrm{ml}$ in PBS) was added to the culture for $4 \mathrm{~h}$ at $37^{\circ} \mathrm{C}$, and then the formazan was dissolved by the addition of dimethyl sulfoxide (DMSO). Absorbance at $570 \mathrm{~nm}$ was measured to determine cell viability. The cell proliferation assay was performed at least three times in ten replicate wells for each concentration tested.

Quantitative real-time RT-PCR ( $q R T-P C R)$. Total RNA was extracted from the cells after the indicated treatment by using the TRIzol reagent (Invitrogen, Carlsbad, CA, USA) according to the instructions provided by the manufacturer. Reverse transcription was performed using $1 \mu \mathrm{g}$ total RNA, yielding $20 \mu \mathrm{l}$ cDNA according to the protocol provided with the Fermentas reagent kit (Thermo Scientific, Waltham, MA, USA). The primers used for specific amplification of target genes (Table I) were synthesized by Sangon Biotech (Shanghai, China). The qRT-PCR was performed using the Fermentas Maxima ${ }^{\mathrm{TM}}$ SYBR Green kit (Thermo Scientific) following the manufacturer's instructions on a Continous Fluorescence Detector (Opticon 2). The real-time qRT-PCR program was $95^{\circ} \mathrm{C}$ for $5 \mathrm{~min}, 35$ cycles at $95^{\circ} \mathrm{C}$ for $15 \mathrm{sec}$, and [Acrp30 receptor 1 (AdipoRl), Acrp30 receptor 2 (AdipoR2) and $G A P D H] 58^{\circ} \mathrm{C} /(\mathrm{Ob}-\mathrm{Rb}) 60^{\circ} \mathrm{C}$ for $45 \mathrm{sec}$ and $72^{\circ} \mathrm{C}$ for $30 \mathrm{sec}$. All real-time PCR experiments were performed in triplicate and results presented as a mean value for the determination of mRNA expression levels. GAPDH served as a loading control.

Cell immunofluorescence. Cell lines were grown on plastic slides and treated with Acrp30, leptin or both before fixing with acetone for $10 \mathrm{~min}$. The cells were incubated with the primary anti-phospho-STAT3 antibody (1:50) for $1 \mathrm{~h}$ in $37^{\circ} \mathrm{C}$, followed by incubation with a fluorescent secondary antibody (1: 200) (Invitrogen) for $45 \mathrm{~min}$, and then restained with Hochest 33342 (1:2000). Olympus BX51 microscope was used for cell immunofluorescence analysis at magnification 

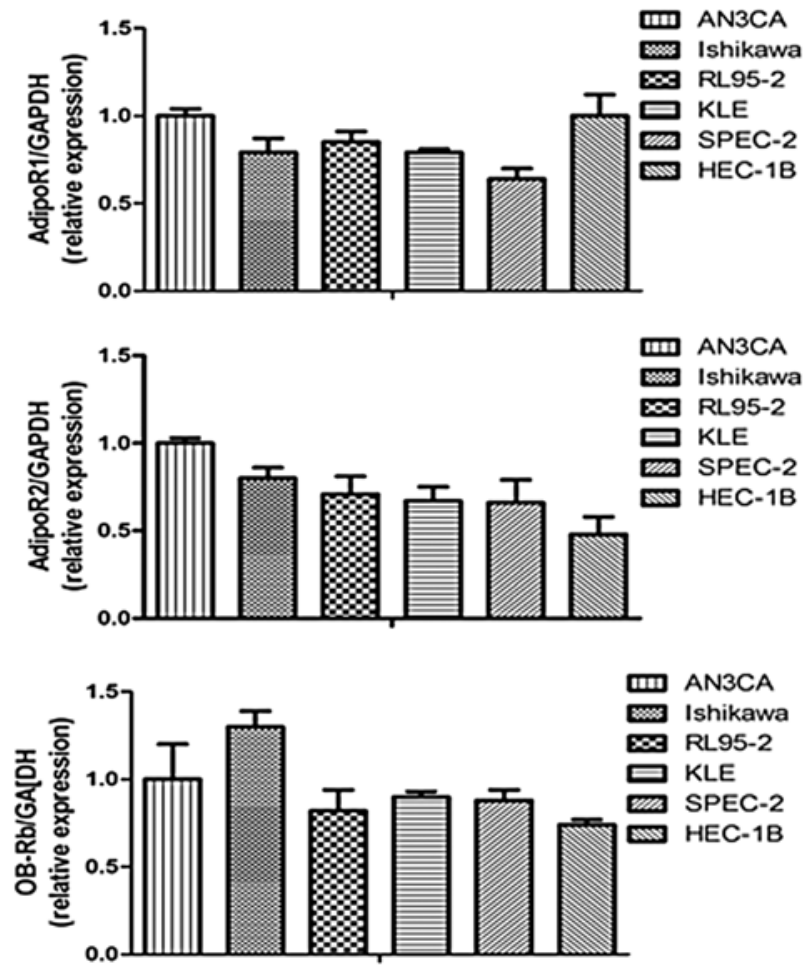

Figure 1. Expression of AdipoR1, AdipoR2 and $O b-R b$ in different endometrial carcinoma cell lines. Total RNA was extracted from AN3CA, Ishikawa, RL95-2, KLE, SPEC-2 and HEC-1B cell lines and analyzed by qRT-PCR as described in Materials and methods. Bars are the means \pm SD obtained from three independent experiments. All data are presented as a fold induction relative to the AN3CA cell line.

of x1000. Imagepro Plus software was used to analyze the fluorescence intensity.

Invasion assay. The ability of cells to migrate through Matrigelcoated filters was determined using 24-well Transwell cell culture chambers. Cells were seeded at a density of $5 \times 10^{4}$ per well and treated with $10 \mu \mathrm{g} / \mathrm{ml}$ Acrp30, $1 \mu \mathrm{g} / \mathrm{ml}$ leptin or both for the indicated times. Cells that had penetrated through the upper chamber and attached to the bottom side of the membrane were fixed by methanol and stained with $5 \%$ crystal violet. After light microscope examination, the cells were eluted with $33 \%$ acetic acid. The OD values of the elution were read using a Bio-Rad Microplate reader at 590-nm wavelength.

Analysis of cell cycle and apoptosis. After SPEC-2 cells were incubated in serum-free medium overnight, they were treated with Acrp30 $(10 \mu \mathrm{g} / \mathrm{ml})$, leptin $(1 \mu \mathrm{g} / \mathrm{ml})$ or both for $48 \mathrm{~h}$. Both floating and trypsinized adherent cells were collected and rinsed with PBS. For cell cycle analysis, the cells were fixed in $70 \%$ ethanol at $4^{\circ} \mathrm{C}$ overnight. Before performing flow cytometry assays, the cells were washed with PBS twice and resuspended in $1 \mathrm{ml}$ PBS containing $0.1 \mathrm{mg}$ RNase (DNase free) for $30 \mathrm{~min}$ at room temperature. The cells were then resuspended with PBS containing $10 \mathrm{mg} / \mathrm{ml}$ propidium iodide (PI; Sigma) and incubated for $15 \mathrm{~min}$ in the dark at room temperature. The DNA content was analyzed using a BD FACStar flow cytometer, and the percentages of different phases of cell cycle were determined using a ModFit program (BD Biosciences, San Jose, CA, USA).
Apoptotic cells were detected with an Annexin-V-FITC kit (BD Biosciences) and PI staining. In this assay, single positive populations are considered early apoptotic (Annexin-V positive) or necrotic cells (PI positive), whereas double positive (Annexin-V positive/PI positive) populations are considered to be in late apoptosis. The staining was performed according to the manual of the manufacturer. Briefly, the cells were incubated in the binding buffer containing Annexin-V-FITC and PI for $15 \mathrm{~min}$ at room temperature. Early and late apoptotic cells were quantified by flow cytometry.

Protein expression analysis. At 70-80\% confluence, treated cells were collected and disrupted in ice-cold cell lysis buffer [Tris-Cl (pH 8.0) 50 mM, NaCl 150 mM, NaN 30.02\%, SDS $0.1 \%$, NP-4 0.1\%, NaTDC $0.5 \%$, EDTA $1 \mathrm{mM}$ ] for protein extraction. Cell lysates were centrifuged at $12,000 \mathrm{x} \mathrm{g}$ for $10 \mathrm{~min}$ at $4^{\circ} \mathrm{C}$. Protein concentrations were determined using a BCA protein assay kit (Thermo Scientific). Equal amounts of proteins were separated by $10 \%$ SDS-polyacrylamide gel electrophoresis (SDS-PAGE) and transferred to polyvinylidene fluoride membranes (Millipore, Billerica, USA). Membranes were blocked with 5\% skimmed milk for $1 \mathrm{~h}$ and incubated overnight with the primary antibodies $(1: 1000)$, followed by incubation with the appropriate secondary horseradish peroxidase-conjugated antibody (1:5000). Signal detection for each protein was performed using an Enhanced Chemiluminescence reagent (Perkin Elmer, Waltham, USA).

Data analysis. All values were expressed as means \pm standard deviation (SD) of three to five separate experiments. One-way ANOVA with Dunnett's post test was performed where appropriate using SPSS 17.0 software with significance accepted at $\mathrm{P}<0.05$.

\section{Results}

Expression of AdipoR1, AdipoR2 and $O b-R b$ in different endometrial carcinoma cell lines. Previous studies have identified two types of Acrp30 receptors, AdipoR1 and AdipoR2 in HEC-1A and RL95-2 endometrial carcinoma cell lines, and $\mathrm{Ob}-\mathrm{Rb}$ in Ishikawa and AN3CA cell lines (1). Using qRT-PCR with oligonucleotide primers specific for transcripts of the human forms of these three receptors, we found that they were all expressed in different endometrial carcinoma cell lines (Fig. 1).

Effects of Acrp30 and leptin on endometrial carcinoma cell proliferation. Treatment of the cultured Ishikawa and SPEC-2 cells with Acrp30 resulted in dosage-dependent suppressive effects on cell proliferation in these two cell lines. Acrp30 significantly decreased the proliferation of Ishikawa cells and SPEC-2 cells by 41 and $43 \%$ at the concentration of $10 \mu \mathrm{g} / \mathrm{ml}$; and 47 and $49.5 \%$ at the concentration of $20 \mu \mathrm{g} / \mathrm{ml}$, respectively, versus controls at the end of $48 \mathrm{~h}$ of incubation (t-test, $\mathrm{P}<0.05$; Fig. 2A). The lower Acrp30 concentrations $(1 \mu \mathrm{g} / \mathrm{ml}$ and $0.1 \mu \mathrm{g} / \mathrm{ml}$ ) were inefficient in inhibiting cell proliferation.

Leptin significantly increased the proliferation of Ishikawa cells and SPEC-2 cells by $96 \%$ and $92.5 \%$ at the concentration of $1 \mu \mathrm{g} / \mathrm{ml}$; and $109.5 \%$ and $103.5 \%$ at the concentration of $2 \mu \mathrm{g} /$ $\mathrm{ml}$, respectively, versus controls after $48 \mathrm{~h}$ of cultivation (t-test, 
A

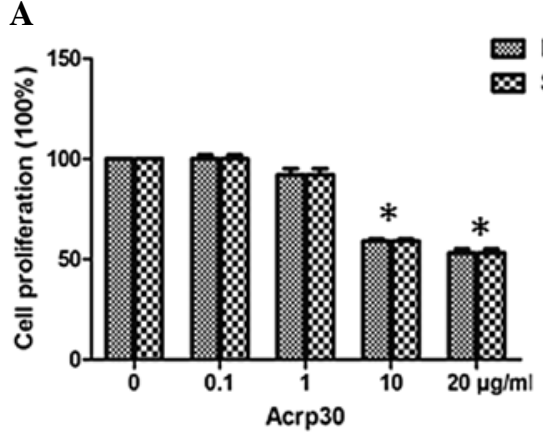

C

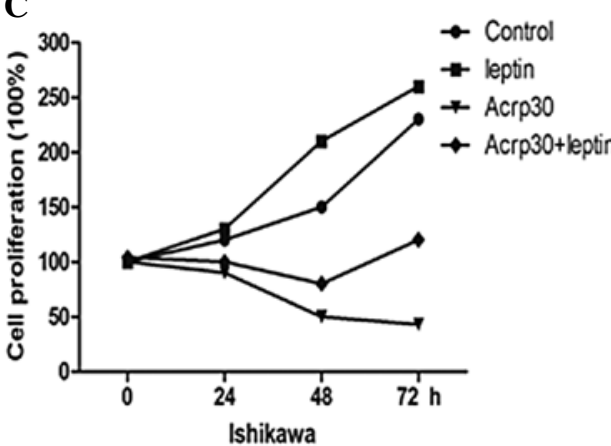

B

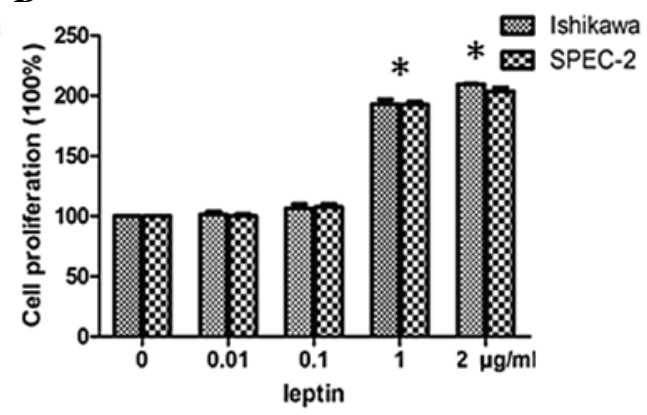

D

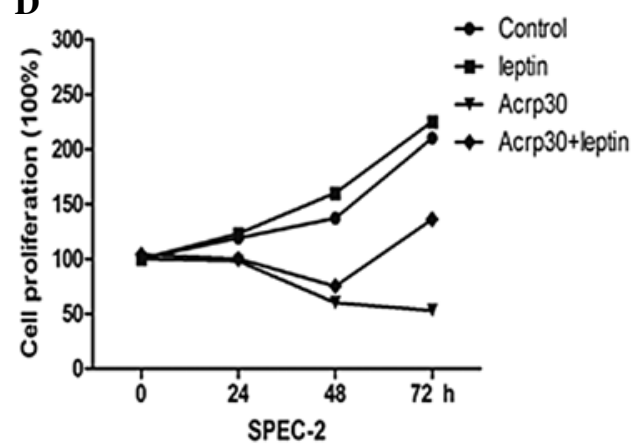

Figure 2. Effects of Acrp30, leptin or both adipokines on proliferation of Ishikawa and SPEC-2 cells. Endometrial carcinoma cells were serum-deprived overnight and then exposed to Acrp30, leptin or both adipokines at different concentrations or for different times as indicated. (A) MTT assay of SPEC-2 and Ishikawa cells after incubation with $0,0.1,1,10$ and $20 \mu \mathrm{g} / \mathrm{ml}$ Acrp30 for $48 \mathrm{~h}$. (B) MTT assay of SPEC-2 and Ishikawa cells after incubation with $0,0.01$,

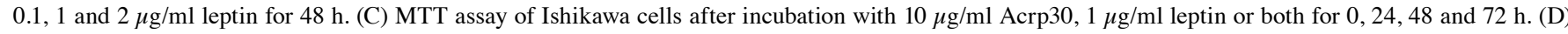
MTT assay of SPEC-2 cells after incubation with $10 \mu \mathrm{g} / \mathrm{ml}$ Acrp30, $1 \mu \mathrm{g} / \mathrm{ml}$ leptin or both for $0,24,48$ and $72 \mathrm{~h}$. Bars are the means \pm SD obtained from three determinations for each cell line, with 6 replicates for each data point. " $\mathrm{P}<0.05$ versus untreated control.

$\mathrm{P}<0.05$; Fig. 2B). The lower leptin concentrations $(0.1 \mu \mathrm{g} / \mathrm{ml}$ and $0.01 \mu \mathrm{g} / \mathrm{ml}$ ) were inefficient in reducing cell proliferation.

In order to determine the effect of both adipokines on proliferation of these cells, we co-treated the two cell lines with Acrp30 and leptin at the concentrations of 10 and $1 \mu \mathrm{g} / \mathrm{ml}$, respectively. We found that Acrp30 significantly inhibited leptin-stimulated cell proliferation at 48 and $72 \mathrm{~h}$ in Ishikawa cells, and similar results were also observed in SPEC-2 cells (t-test, P<0.05; Fig. 2C and D).

Effects of Acrp30 and leptin on cell cycle and apoptosis in SPEC-2 cells. Based on the observation that responses of SPEC-2 cells to Acrp30 and leptin co-treatment in the proliferation assays were similar to those of Ishikawa cells, we conducted subsequent experiments only on the more aggressive SPEC-2 cells. SPEC-2 cells demonstrated significant changes in apoptotic responses following treatment with $10 \mu \mathrm{g} / \mathrm{ml}$ Acrp30, $1 \mu \mathrm{g} / \mathrm{ml}$ leptin or both for $48 \mathrm{~h}$ in serum-free medium, as assessed by flow cytometry analysis (Fig. 3A). We observed a significant increase in the percentage $(14.4 \%)(\mathrm{P}<0.05)$ of early stage apoptotic cells treated with Acrp30 as revealed by the Annexin- $\mathrm{V}$ staining positive patterns. In contrast, an apoptosis rate $(3.25 \%)(\mathrm{P}<0.05)$ lower than untreated cells was observed in SPEC-2 treated with leptin alone, and this apoptosis rate was significantly elevated to $8.25 \%(\mathrm{P}<0.05)$ in the presence of both adipokines.

To further explore the anti-proliferative actions of Acrp30 and pro-proliferative effects of leptin, we analyzed the changes in cell cycles by flow cytometry. Acrp30 increased the percentage of SPEC- 2 cells in G1/G0-phase from $48.87 \%$ to $71.14 \%(\mathrm{P}<0.05)$, and leptin decreased the percentage of SPEC-2 cells in G1/G0-phase from 48.77 to $45.65 \%$ ( $\mathrm{P}<0.05)$. Meanwhile, the percentage of cells in G1/G0-phase was reduced to $50.62 \%$ when co-treated with these two adipokines compared with leptin treatment alone $(\mathrm{P}<0.05)$. Concomitant with these changes, the percentage of SPEC-2 cells in S-phase was decreased from 46.93 to $14.21 \%(\mathrm{P}<0.05)$ when treated with Acrp30, and increased from 46.93 to $53.51 \%(\mathrm{P}<0.05)$ when treated with leptin. Co-treatment with these two adipokines decreased the proportion of SPEC-2 cells in S-phase from 46.93 to $42.60 \%$ compared with control $(\mathrm{P}<0.05)$ (Fig. 3B).

Influence of Acrp30 and leptin on cell metastasis. To determine the direct effects of these two adipokines on the invasiveness of endometrial cancer cells, we performed Matrigel invasion assays with SPEC-2 cells (Fig. 4A). The invasiveness of these cells was significantly reduced (66\%) $48 \mathrm{~h}$ after treatment with Acrp30 compared with untreated cells, while it was promoted $(65 \%)$ after treatment with leptin. The invasive cells were effectively reduced (53\%) by co-treatment with Acrp30 and leptin when compared to leptin treatment alone.

We detected the levels of two invasion-related proteins, MMP-2 and MMP-9, by western blotting. At $48 \mathrm{~h}$ after leptin treatment of SPEC-2 cells, the MMP-2 protein levels were 2.26-fold higher relative to the control (Fig. 4B). Conversely, MMP-2 protein levels were significantly downregulated by Acrp30 treatment after $48 \mathrm{~h}$ of incubation. Levels of MMP-9 in SPEC-2 cells co-treated with these two adipokines were lower than those in leptin-only treated cells. Thus, the MMP-9 protein expression exhibited a pattern similar to that 
A
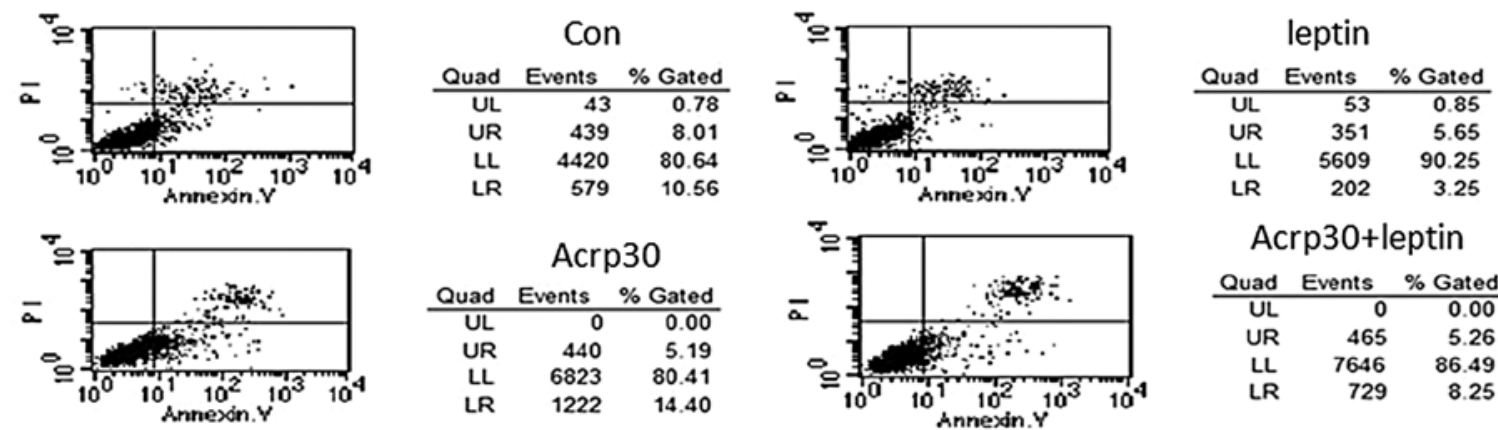

Acrp30

\begin{tabular}{rrr} 
Quad & Events & $\%$ Gated \\
\hline UL & 0 & 0.00 \\
UR & 440 & 5.19 \\
LL & 6823 & 80.41 \\
LR & 1222 & 14.40
\end{tabular}

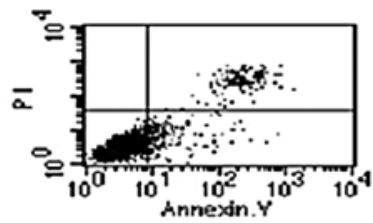

Acrp30+leptin

\begin{tabular}{crr} 
Quad & Events & $\%$ Gated \\
\hline UL & 0 & 0.00 \\
UR & 465 & 5.26 \\
LL & 7646 & 86.49 \\
LR & 729 & 8.25
\end{tabular}

B

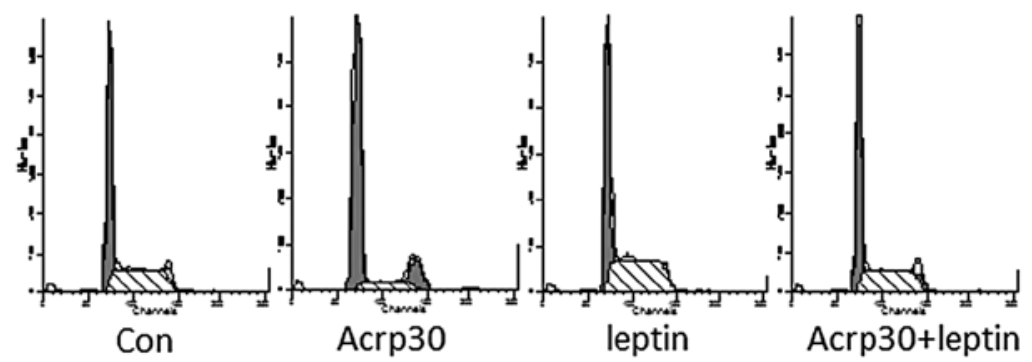

\begin{tabular}{|c|c|c|c|}
\hline & Con & Acrp30 leptin & Acrp30+leptin \\
\hline G0-G1 & $48.77 \%$ & $71.14 \%{ }^{*} 45.65 \%$ * & $50.62 \%$ \\
\hline G2-M & $4.30 \%$ & $14.65 \%$ & $6.78 \%$ \\
\hline$S$ & $46.93 \%$ & $14.21 \%{ }^{*} 53.51 \%$ * & ${ }^{*} 42.60 \%{ }^{*}$ \\
\hline
\end{tabular}

Figure 3. Flow cytometry analysis of cell cycle and apoptosis in SPEC-2 cells after treatment with Acrp30, leptin or both adipokines. SPEC-2 cells were incubated with Acrp30 $(10 \mu \mathrm{g} / \mathrm{ml})$, leptin $(1 \mu \mathrm{g} / \mathrm{ml})$ or both for $48 \mathrm{~h}$ after being serum-starved overnight. At the end of the incubation, the cells were collected for FACS analysis. (A) Apoptosis of SPEC-2 cells analyzed by FACS after different treatments. (B) Cell cycle of SPEC-2 cells analyzed by FACS after different treatments. Values shown are means \pm SD. Experiments were repeated a minimum of 3 times for each treatment or control. "P<0.05 versus untreated control.

of MMP-2 when the SPEC-2 cells were treated with Acrp30, leptin or both.

Leptin-activated STAT3 phosphorylation and nuclear localization are reversed by Acrp30. To understand the potential molecular mechanisms underlying the anti-invasion effects of Acrp30 and pro-invasion effects of leptin on SPEC-2 cells, we evaluated STAT3 signaling events induced by leptin (23). We found that STAT3 could be inactivated by Acrp30 treatment within 30 min in SPEC-2 cells, which was evident by the decrease in phosphorylated STAT3 (at Ser727) (Fig. 5A) in a dosage-dependent manner (Fig. 5B). Co-treatment with Acrp30 inhibited the leptin-induced phosphorylation of STAT3 (Fig. 5C).

As a transcriptional regulator, STAT3 function is highly dependent upon its cellullar localization. Leptin treatment led to the translocation of STAT3 from the cytoplasm to the nucleus, whereas activated (phosphorylated) STAT3 was reduced in the nucleus when treated with Acrp30. Treatment with Acrp30 prevented the leptin-induced nuclear localization of STAT3 (Fig. 5C). This result indicates that the observed invasive characteristics of SPEC-2 cells may be substantially attributed to the STAT3 signaling pathways regulated by Acrp30 and leptin.

Acrp30 inhibition of leptin-mediated invasion is regulated by AMPK and JAK/STAT3 signaling pathways. Dephosphorylation of STAT3 decreases its translocation activity. Therefore, it was expected that Acrp30-activated AMPK would stimulate the dephosphorylation of STAT3, resulting in decreased invasiveness of SPEC-2 cells. To test this possibility, the levels of phosphorylated STAT3 were measured in cells with various treatments as shown in Fig. 6A. As expected, Acrp30 significantly induced the phosphorylation of AMPK and inhibited the phosphorylation of STAT3 at the same time. Conversely, Compound C, a suppressor of AMPK, inhibited the phosphorylation of AMPK, it while stimulated the phosphorylation of STAT3. The low level of phospho-AMPK and high level of phospho-STAT3 induced by leptin were reversed by Acrp30 co-treatment. The protein expression levels of total AMPK and STAT3 were not altered by the different treatments in SPEC-2 cells.

In order to determine whether inhibition of STAT3 activity by Acrp30 was the main pathway controlling the attenuated invasion, two invasion-related proteins, MMP-2 and MMP-9, were detected in SPEC-2 cells with various treatments as shown in Fig. 6B. We found that leptin and IL-6 (a well-known STAT3 activator) were able to activate STAT3 and obviously increased MMP-2 and MMP-9 levels in SPEC-2 cells. However, the levels of both proteins significantly decreased, accompanied by the dephosphorylation of STAT3, when treated with Acrp30. Treatment with AG490 (a well-known STAT3 inhibitor) resulted in a similar effect on MMP-2 and MMP-9 expression as with the Acrp30 treatment in SPEC-2 cells. Therefore, high levels of phospho-STAT3, MMP-2 and MMP-9 induced by leptin or IL-6 could be significantly reversed by Acrp30 or AG490.

\section{Discussion}

Endometrial cancer is the most common gynecological malignancy and the fourth most common cancer among women in 

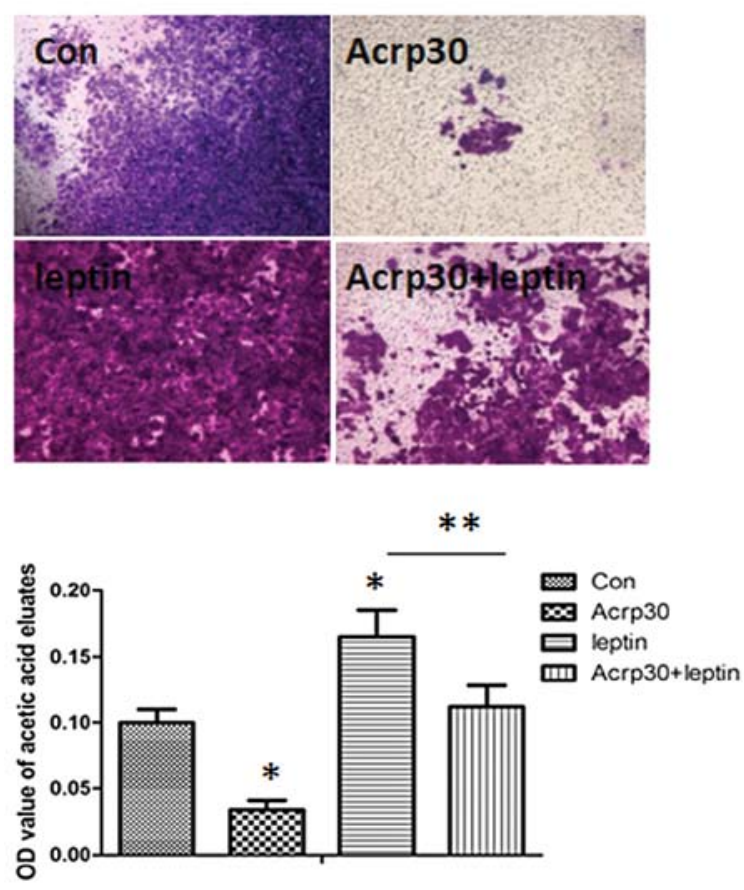

B
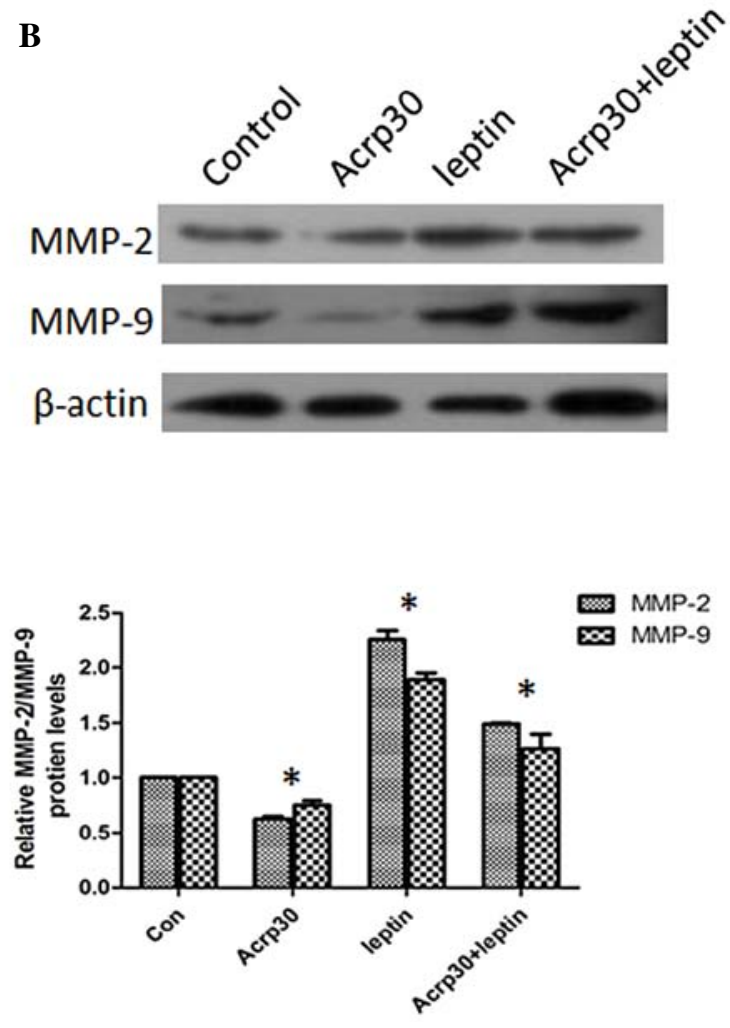

Figure 4. Analysis of invasiveness of SPEC-2 cells treated with Acrp30, leptin or both adipokines. (A) SPEC-2 cells were serum-starved overnight and then

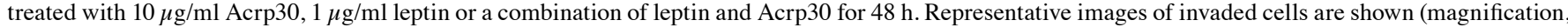
$\mathrm{x} 100$ ), and OD values of permeated cells eluted in 33\% acetic acid elution were compared. Experiments were repeated twice. (B) Protein expressions of MMP-2 and MMP-9 in SPEC-2 cells treated as above were analyzed by western blotting using specific antibodies, and $\beta$-actin was detected as a loading control. Results are representative of five separate experiments. ${ }^{*} \mathrm{P}<0.05$ versus untreated control.

A

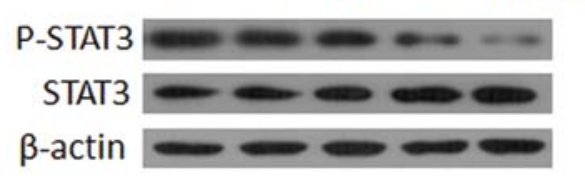

B

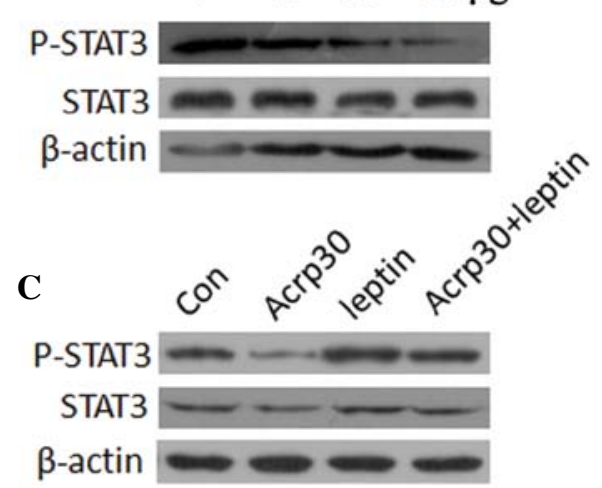

D

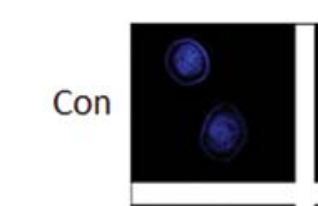

Acrp30
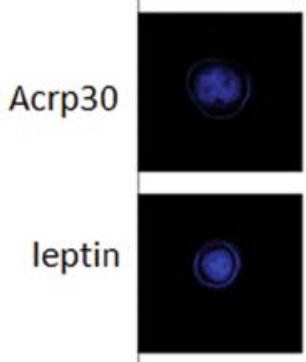

Acrp30 +leptin

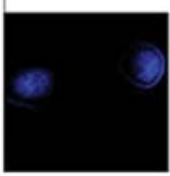

DAPI
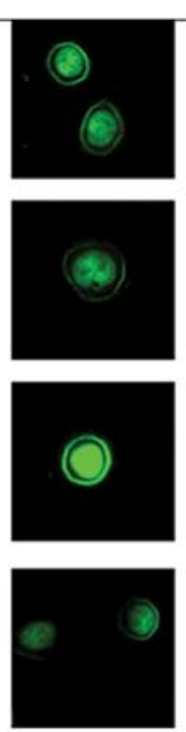

STAT3-P
Relative nucleus intensity of STAT3
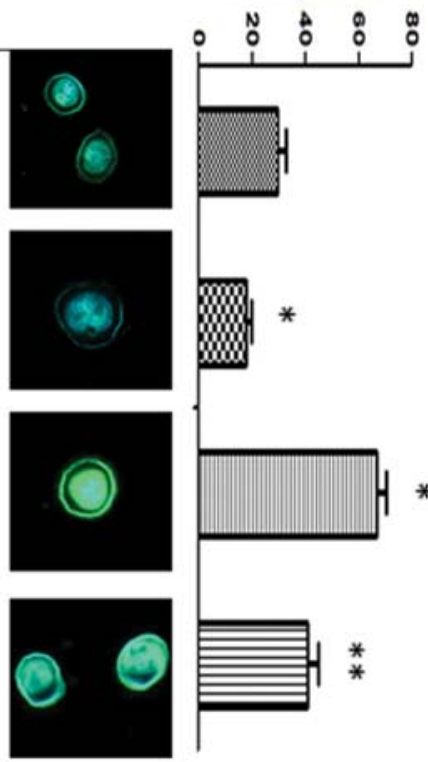

Merge

Figure 5. Leptin-induced phosphorylation and nuclear localization of STAT3 were reversed by Acrp30. (A) SPEC-2 cells were serum-starved overnight and then treated with $10 \mu \mathrm{g} / \mathrm{ml}$ Acrp30 for the indicated time. Phosphorylated STAT3 levels were examined by western blotting. (B) Phosphorylated STAT3 levels were examined in SPEC-2 cells treated with different concentrations of Acrp30 for $1 \mathrm{~h}$. (C) Phosphorylated STAT3 levels were examined in SPEC-2 cells treated with Acrp30, leptin or both for $1 \mathrm{~h}$. (D) Cells were treated with $10 \mu \mathrm{g} / \mathrm{ml}$ Acrp30, $1 \mu \mathrm{g} / \mathrm{ml}$ leptin or both for $2 \mathrm{~h}$, and endogenous localization of STAT3 was examined by fluorescence microscopy using an anti-phospho-STAT3 antibody. Images were quantified using Imagepro plus software. Results are representative of three to five separate experiments. ${ }^{*} \mathrm{P}<0.05$ versus untreated control; ${ }^{* *} \mathrm{P}<0.05$ versus leptin treated cells. 
A

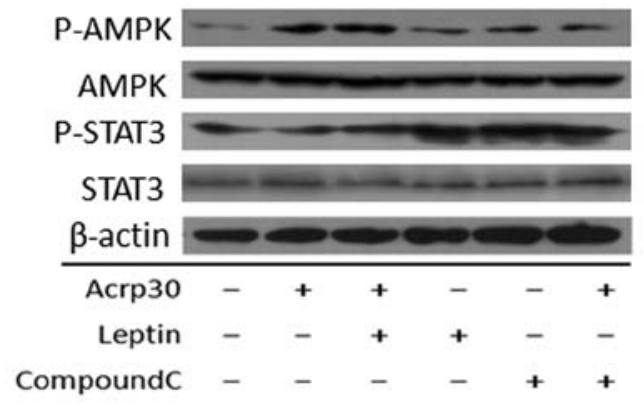

B

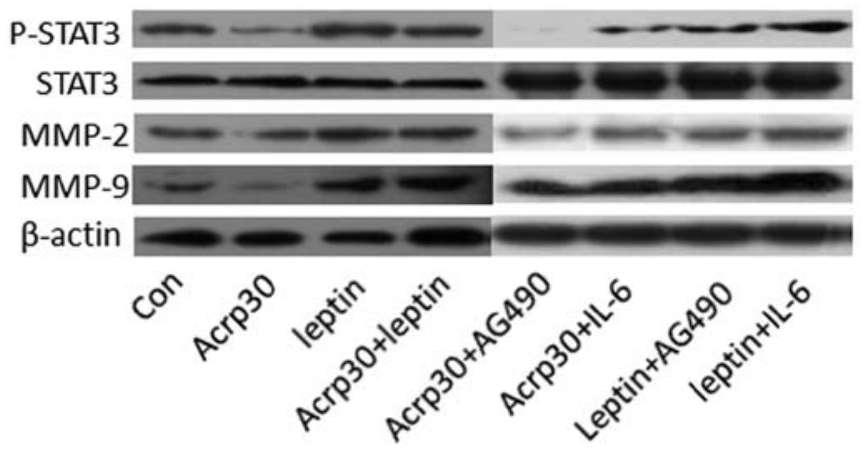

Figure 6. Cell signaling involved in opposing effects of Acrp30 and leptin on SPEC-2 invasion. (A) SPEC-2 cells were serum-starved overnight and then treated with $10 \mu \mathrm{g} / \mathrm{ml}$ Acrp30, $1 \mu \mathrm{g} / \mathrm{ml}$ leptin, $5 \mu \mathrm{mol} / 1$ Compound C or indicated combinations for $2 \mathrm{~h}$, and then levels of phosphorylated STAT3 and AMPK were examined by immunoblot analysis. (B) Levels of phosphorylated STAT3 and MMP-2/MM-9 proteins were detected in SPEC-2 cells after 48 h of treatment

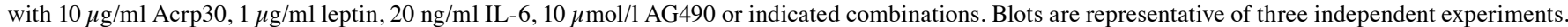
${ }^{*} \mathrm{P}<0.05$ versus untreated control.

the United States. Obesity is a well-known risk factor for endometrial cancer, with the level of risk correlating with the degree of obesity (27). Although the concept of a 'hyperestrogenic' state increasing the risk for endometrial cancer is a well-accepted theory, elevated endogenous estrogens may not fully account for the correlation noted between obesity and endometrial cancer risk (28-32). Acrp30 and leptin, which are both adipocytesecreted hormones deregulated in obesity, may be involved in endometrial cancer development $(2,8)$.

Recent studies reported that obesity is associated with both hypoadiponectinemia and hyperleptinemia, which suggests that tumor cell growth results from the combined stimulatory effects of leptin and anti-proliferative activity of Acrp30 (1). Positive associations between the concentration of circulating leptin and cancer risk have been reported for breast, colon and prostate cancers $(18,33,34)$, and aberrant plasma leptin expression levels are observed in patients with endometrial cancer (35-37). In contrast, inverse relationships of Acrp30 levels and cancer risk have been reported for breast, endometrium and colon cancer $(2,18,38)$. A previous clinical study found elevated L/A ratios in post-menopausal endometrial cancer patients, which were significantly associated with an increased risk of endometrial cancer, and the associations remained after adjusting for obesity indices and other confounding factors (2). The balance of leptin and Acrp30 levels in individuals, rather than the leptin or Acrp30 levels alone, may indicate such physiological changes as the development of cancer (20). Leptin and Acrp30 appear to exert antagonistic activities by downregulating expression of each other's receptor and corresponding signaling pathways $(8,39)$.

As Acrp30 and leptin both have effects on cancer cell proliferation and are related to many signaling pathways such as AMPK and JAK/STAT3, we addressed the question of whether Acrp30 can also inhibit cancer cell invasion stimulated by leptin and investigated the underlying molecular mechanism. As most previous studies were conducted in other endometrial cancer cell lines, here we provide evidence that Acrp30 also inhibited the proliferation of the endometrial cancer SPEC-2 cells. We found that Acrp30 indeed had inhibitory effects towards leptin-mediated invasion which required inactivation of the JAK/STAT3 signaling pathway through activation of the AMPK pathway.

Previous studies have confirmed that Acrp30 inhibits endometrial cancer cell proliferation in a time- and dose-dependent manner (1), while leptin increases proliferation of endometrial $(35,40)$ and many other cancer cells $(41)$. Activation of AMPK with Acrp30 treatment can inhibit proliferation of many types of cancer cells and induce apoptosis (42), while activation of STAT3 is essential for the cell proliferative effect of leptin in endometrial carcinoma (43). Similar to previous studies, we found that Acrp30 could activated AMPK and inhibit leptinstimulated SPEC-2 cell proliferation by analysis of cell cycle arrest and apoptosis levels.

Cancer progression is a multi-step process that involves invasion of the basement membrane by tumor cells and migration to points far from a given primary tumor mass leading to metastasis. Previous research has found that Acrp30 suppresses the metastasis of cancer cells through AKT inactivation in breast cancer cells (5). Acrp30 can also downregulate KRT18 mRNA (a gene related to tumor metastasis), while leptin upregulates MUC1 (an anti-adhesion molecule) in breast cancer cells to regulate aggressiveness of tumor cells (44). Leptin can promote invasiveness of colonic and kidney epithelial cells at various stages of neoplastic transformation, and leptin-induced invasion is completely blocked by pharmacological inhibitors of JAK2 (AG490) at $50 \mu \mathrm{M}$ (45). Additionally, leptin can trigger invasion of ECC endometrial cancer cells via a pathway involving both PI3K and JAK/STAT3 pathways, as pharmacological inhibition of these pathways abolishes leptin-induced invasiveness (43).

In this study, we demonstrated that the enhancement of SPEC-2 cell invasion by leptin could be significantly reversed with Acrp30 treatment. When examining potential mechanisms involved in this invasion processs, we observed that phosphorylated STAT3 levels were below basal within 30 min following Acrp30 or Acrp30/leptin treatment in SPEC-2 cells. Leptininduced nuclear translocation of STAT3 was significantly inhibited by Acrp30 in SPEC-2 cells. The invasion inhibition and STAT3 dephosphorylation effect of Acrop30 against leptin 
could be abolished by Compound C, an AMPK inactivator, demonstrating the important role of AMPK in STAT3 activation and invasion. In order to gain further insight into the mechanisms whereby STAT3 activation increases SPEC-2 cell invasion, we investigated the expressions of the invasionrelated MMP2 and MMP-9 proteins. These two proteins were also positively correlated with STAT3 activation and could be decreased by AG490, a STAT3 pathway inhibitor, and increased by IL-6, a STAT3 pathway activator. These results indicated that MMP-2 and MMP-9 may be the potential target proteins of STAT3.

In summary, our study for the first time uncovered the molecular mechanisms responsible for the Acrp30 inhibition of leptin-induced invasion of SPEC-2 endometrial cancer cells, i.e., via inactivation of the JAK2/STAT3 signaling pathway by activating AMPK. Hence, together with other in vitro studies, our findings support these two adipokines to be molecular mediators between obesity and the progression of endometrial cancer. Targeting these pathways may be a suitable therapeutic strategy for endometrial cancer progression associated with the coordinated effects of leptin and Acrp30.

\section{References}

1. Cong L, Gasser J, Zhao J, Yang B, Li F and Zhao AZ: Human adiponectin inhibits cell growth and induces apoptosis in human endometrial carcinoma cells, HEC-1-A and RL95 2. Endocr Relat Cancer 14: 713-720, 2007.

2. Ashizawa N, Yahata T, Quan J, Adachi S, Yoshihara K and Tanaka K: Serum leptin-adiponectin ratio and endometrial cancer risk in postmenopausal female subjects. Gynecol Oncol 119: 65-69, 2010.

3. Judd HL, Shamonki IM, Frumar AM and Lagasse LD: Origin of serum estradiol in postmenopausal women. Obstet Gynecol 59: 680-686, 1982

4. Berstein LM, Kvatchevskaya JO, Poroshina TE, et al: Insulin resistance, its consequences for the clinical course of the disease, and possibilities of correction in endometrial cancer. J Cancer Res Clin Oncol 130: 687-693, 2004.

5. Kim KY, Baek A, Hwang JE, et al: Adiponectin-activated AMPK stimulates dephosphorylation of AKT through protein phosphatase 2A activation. Cancer Res 69: 4018-4026, 2009.

6. Dalamaga M, Migdalis I, Fargnoli JL, et al: Pancreatic cancer expresses adiponectin receptors and is associated with hypoleptinemia and hyperadiponectinemia: a case-control study. Cancer Causes Control 20: 625-633, 2009.

7. Otake S, Takeda H, Fujishima S, et al: Decreased levels of plasma adiponectin associated with increased risk of colorectal cancer. World J Gastroenterol 16: 1252-1257, 2010.

8. Jarde T, Caldefie-Chezet F, Goncalves-Mendes N, et al: Involvement of adiponectin and leptin in breast cancer: clinical and in vitro studies. Endocr Relat Cancer 16: 1197-1210, 2009.

9. Maeda K, Okubo K, Shimomura I, Funahashi T, Matsuzawa Y and Matsubara K: cDNA cloning and expression of a novel adipose specific collagen-like factor, apM1 (AdiPose Most abundant Gene transcript 1). Biochem Biophys Res Commun 221: 286-289, 1996.

10. Nkhata KJ, Ray A, Schuster TF, Grossmann ME and Cleary MP: Effects of adiponectin and leptin co-treatment on human breast cancer cell growth. Oncol Rep 21: 1611-1619, 2009.

11. Takemura Y, Osuga Y, Yamauchi T, et al: Expression of adiponectin receptors and its possible implication in the human endometrium. Endocrinology 147: 3203-3210, 2006.

12. Nakayama S, Miyoshi Y, Ishihara H and Noguchi S: Growthinhibitory effect of adiponectin via adiponectin receptor 1 on human breast cancer cells through inhibition of S-phase entry without inducing apoptosis. Breast Cancer Res Treat 112: 405-410, 2008

13. Landskroner-Eiger S, Qian B, Muise ES, et al: Proangiogenic contribution of adiponectin toward mammary tumor growth in vivo. Clin Cancer Res 15: 3265-3276, 2009.
14. De Vos P, Saladin R, Auwerx J and Staels B: Induction of ob gene expression by corticosteroids is accompanied by body weight loss and reduced food intake. J Biol Chem 270: 15958-15961, 1995.

15. Mounzih K, Lu R and Chehab FF: Leptin treatment rescues the sterility of genetically obese ob/ob males. Endocrinology 138: 1190-1193, 1997.

16. Lago F, Dieguez C, Gomez-Reino J and Gualillo O: The emerging role of adipokines as mediators of inflammation and immune responses. Cytokine Growth Factor Rev 18: 313-325, 2007.

17. Jarde T, Caldefie-Chezet F, Damez M, et al: Leptin and leptin receptor involvement in cancer development: a study on human primary breast carcinoma. Oncol Rep 19: 905-911, 2008.

18. Guadagni F, Roselli M, Martini F, et al: Prognostic significance of serum adipokine levels in colorectal cancer patients. Anticancer Res 29: 3321-3327, 2009.

19. Chen DC, Chung YF, Yeh YT, et al: Serum adiponectin and leptin levels in Taiwanese breast cancer patients. Cancer Lett 237: 109-114, 2006.

20. Cleary MP, Ray A, Rogozina OP, Dogan S and Grossmann ME: Targeting the adiponectin:leptin ratio for postmenopausal breast cancer prevention. Front Biosci (Schol Ed) 1: 329-357, 2009.

21. Chen CL, Hsieh FC, Lieblein JC, et al: Stat3 activation in human endometrial and cervical cancers. Br J Cancer 96: 591-599, 2007.

22. Yin N, Wang D, Zhang H, et al: Molecular mechanisms involved in the growth stimulation of breast cancer cells by leptin. Cancer Res 64: 5870-5875, 2004.

23. Jiang $\mathrm{H}$, Yu J, Guo H, Song $\mathrm{H}$ and Chen S: Upregulation of survivin by leptin/STAT3 signaling in MCF-7 cells. Biochem Biophys Res Commun 368: 1-5, 2008.

24. Yamauchi T, Kamon J, Minokoshi Y, et al: Adiponectin stimulates glucose utilization and fatty-acid oxidation by activating AMP-activated protein kinase. Nat Med 8: 1288-1295, 2002.

25. Jarde T, Perrier S, Vasson MP and Caldefie-Chezet F: Molecular mechanisms of leptin and adiponectin in breast cancer. Eur J Cancer 47: 33-43, 2011.

26. Taliaferro-Smith L, Nagalingam A, Zhong D, Zhou W, Saxena NK and Sharma D: LKB1 is required for adiponectin-mediated modulation of AMPK-S6K axis and inhibition of migration and invasion of breast cancer cells. Oncogene 28: 2621-2633, 2009.

27. Soliman PT, Cui X, Zhang Q, Hankinson SE and Lu KH: Circulating adiponectin levels and risk of endometrial cancer: the prospective Nurses' Health Study. Am J Obstet Gynecol 204: 167 e161-e165, 2011.

28. Nyholm HC, Nielsen AL, Lyndrup J, Dreisler A, Hagen C and Haug E: Plasma oestrogens in postmenopausal women with endometrial cancer. Br J Obstet Gynaecol 100: 1115-1119, 1993.

29. Pettersson B, Bergstrom R and Johansson ED: Serum estrogens and androgens in women with endometrial carcinoma. Gynecol Oncol 25: 223-233, 1986.

30. Benjamin F and Deutsch S: Plasma levels of fractionated estrogens and pituitary hormones in endometrial carcinoma. Am J Obstet Gynecol 126: 638-647, 1976.

31. Judd HL, Davidson BJ, Frumar AM, Shamonki IM, Lagasse LD and Ballon SC: Serum androgens and estrogens in postmenopausal women with and without endometrial cancer. Am J Obstet Gynecol 136: 859-871, 1980.

32. Calanog A, Sall S, Gordon GG and Southren AL: Androstenedione metabolism in patients with endometrial cancer. Am J Obstet Gynecol 129: 553-556, 1977.

33. Wu MH, Chou YC, Chou WY, et al: Circulating levels of leptin, adiposity and breast cancer risk. Br J Cancer 100: 578-582, 2009.

34. Li H, Stampfer MJ, Mucci L, et al: A 25-year prospective study of plasma adiponectin and leptin concentrations and prostate cancer risk and survival. Clin Chem 56: 34-43, 2010.

35. Petridou E, Belechri M, Dessypris N, et al: Leptin and body mass index in relation to endometrial cancer risk. Ann Nutr Metab 46: 147-151, 2002.

36. Tessitore L, Vizio B, Pesola D, et al: Adipocyte expression and circulating levels of leptin increase in both gynaecological and breast cancer patients. Int J Oncol 24: 1529-1535, 2004.

37. Yuan SS, Tsai KB, Chung YF, et al: Aberrant expression and possible involvement of the leptin receptor in endometrial cancer. Gynecol Oncol 92: 769-775, 2004.

38. Tworoger SS, Eliassen AH, Kelesidis T, et al: Plasma adiponectin concentrations and risk of incident breast cancer. J Clin Endocrinol Metab 92: 1510-1516, 2007.

39. Dos Santos E, Benaitreau D, Dieudonne MN, et al: Adiponectin mediates an antiproliferative response in human MDA-MB 231 breast cancer cells. Oncol Rep 20: 971-977, 2008. 
40. Kaaks R, Lukanova A and Kurzer MS: Obesity, endogenous hormones, and endometrial cancer risk: a synthetic review. Cancer Epidemiol Biomarkers Prev 11: 1531-1543, 2002.

41. Saxena NK, Taliaferro-Smith L, Knight BB, et al: Bidirectional crosstalk between leptin and insulin-like growth factorsignaling promotes invasion and migration of breast cancer cells via transactivation of epidermal growth factor receptor. Cancer Res 68: 9712-9722, 2008

42. Rattan R, Giri S, Singh AK and Singh I: 5-Aminoimidazole4-carboxamide-1-beta-D-ribofuranoside inhibits cancer cell proliferation in vitro and in vivo via AMP-activated protein kinase. J Biol Chem 280: 39582-39593, 2005.
43. Sharma D, Saxena NK, Vertino PM and Anania FA: Leptin promotes the proliferative response and invasiveness in human endometrial cancer cells by activating multiple signal-transduction pathways. Endocr Relat Cancer 13: 629-640, 2006.

44. Buhler H and Schaller G: Transfection of keratin 18 gene in human breast cancer cells causes induction of adhesion proteins and dramatic regression of malignancy in vitro and in vivo. Mol Cancer Res 3: 365-371, 2005.

45. Attoub S, Noe V, Pirola L, et al: Leptin promotes invasiveness of kidney and colonic epithelial cells via phosphoinositide 3-kinase-, rho-, and rac-dependent signaling pathways. FASEB J 14: 2329-2338, 2000. 